\title{
Perceived Safety and Security Concerns among Tourists in Thamel-A Tourism Hub in Kathmandu Valley, Nepal
}

Indonesian Journal of Tourism and Leisure, 2020
Vol. 01 (2), $92-102$
(C) The Journal, 2020
DOI: $10.36256 /$ ijtl.v1i2.122
https: / / journal.lasigo.org/index.php/IJTL
Article History
Received: November $3^{\text {rd }}, 2020$
Revised: December $19^{t h}, 2020$
Accepted: December $21^{t}, 2020$

\section{Arun Kumar Sharma}

Department of Strategic Studies, Faculties of Humanities and Social Science, Tribhuvan University, Kathmandu Email: arunapf@gmail.com

\section{Birendra KC}

Department of Hospitality and Tourism Management, College of Merchandising, Hospitality \& Tourism, University of North Texas

Email: birendra.kc@unt.edu

\section{Araceli Hernandez Calderon}

Department of Hospitality and Tourism Management, College of Merchandising, Hospitality \& Tourism, University of North Texas

Email: Araceli.HernandezCalderon@unt.edu

\begin{abstract}
The safety and security of a destination is an essential factor that helps travelers decide whether to visit or not. In Nepal, Thamel is the main destination for tourists due to the availability of multiple facilities and services. In fact, most of the tourists who use airspace to travel to Nepal, start and conclude their journey in Thamel. Therefore, the safety and security of Thamel is an important factor that influences the fate of the Nepalese tourism industry. However, there is a lack of research to understand the safety and security situation of Thamel. The purpose of this exploratory study is to assess the overall security situation and challenges in Thamel. Descriptive statistics are used to present the findings. Findings suggest that Thamel as a tourism destination has many areas for improvement to provide better tourist experiences. Since Thamel is a starting and concluding point of attraction for tourists, we offer important managerial implications and future research directions.
\end{abstract}

Keywords: Safety; security; tourism; sustainability; Nepal

\section{Introduction}

The tourism sector is emerging as a major driving force for economic growth and development in the modern world. Traveling is not only developing as a hobby for people but also as a fashion, behavior, and lifestyle. It has been established as the largest industry in the world which is instrumental in generating income and large-scale employment (Gammon \& Robinson, 2003). Mainly, people visit different places for four purposes: to explore nature, to understand the culture, to have entertainment, and as a religious pilgrimage. Besides these, people also travel for research, adventure, study, business, and as a part of the employment. Currently, new avenues of 
tourism are also coming up such as sports tourism and health tourism (Garcia-Altes, 2005). The tourism industry is facing many challenges. One of the most important challenges is the issue of safety and security. The safety and security status of a place is always a matter of concern for travel-related decision-making (Walters et al., 2017). Though the concept of safety and security is not novel, it has gained much momentum in the last couple of decades. The civil wars in many countries, rising terrorism, natural disasters, epidemics, and pandemics might be the reasons for increased concern for safety and security (Kovari \& Zimanyi, 2011).

The state of safety and security situation of a place determines its success. There is a growing trend among people to travel to new places as tourism phenomena are expanding across the globe. International tourism reached 1.5 billion in 2019 (WTO, 2020), raising hope for many destinations to support their socio-economic development process. However, challenges exist to harness the socio-economic benefits of tourism. In this modern era of communication and technology, insecurity and crime-related information are easily transmitted from one corner of the world to another. With the spread of news of vulnerable security situation, tourists are more likely to avoid traveling to those destinations. With many alternatives available globally, tourists choose more secure places rather than risking their lives in an insecure environment. Traveling in areas with compromised security does not allow peace of mind in prospective tourists and with high perceived risk deterring a decision to travel (Garg, 2015; Sharma, 2017).

The concept of tourism and security always go together. The perception of the security of a place will determine tourist's decision-making process for visitation (Garg, 2015). For example, war events that occurred in Iraq in 2003, the spread of diseases such as SARS in Hong Kong in early 2000, Zika virus in 2015 in South America negatively affected their tourism industry which indicates that the tourism industry is highly vulnerable to general security as well as other security threats such as health issues (Hall et al., 2004, 2020). Also, if only a portion of the country is affected by civil war or any global health problem, the whole country's tourism flow will decrease because of the insecure feeling among the tourists. Thus, safety and security concerns in one specific destination can negatively impact the overall regional or national tourism destinations and tourism revenue. Particularly, the gateway tourism destinations and their state of safety and security situations are crucial because they are often considered the reference points for other destinations.

The number of tourists visiting Nepal is increasing on average. There are different niche tourism markets for Nepal including nature-based tourism/ecotourism, cultural tourism, pilgrimage tourism, adventure tourism, mountain tourism, etc. In 2018, Nepal received over 1.1 million international tourists, the highest recorded number in the history of Nepalese tourism (Ministry of Culture, Tourism and Civil Aviation [MoCTCA], 2019). The number of tourists increases when the political situation is stable and there are no pertinent security threats in the country. However, the Nepalese tourism industry and the flow of international tourists had been interrupted over the years. These fluctuations are intricately associated with the sociopolitical context of the country. Due to the vulnerable sociological environment, safety and security situations are often compromised. For example, the number of tourists was low in Nepal during the ten years of the Maoists insurgency and the earthquake in 2015 (Rasul \& Manandhar, 2009; Min et al., 2020).

The Government of Nepal is proactively trying to increase its stake on the international tourism market due to its rich potential to capture different segments of tourists. Different forms of tourism including ecotourism, pro-poor tourism, homestay tourism, are promoted to support rural livelihoods and their socio-economic wellbeing (KC et al., 2018; KC, 2020; UNDP, 2007; Walter et al., 2018). The growth of international tourists' number from 9,526 in 1964 to over 1.1 million until 2019 (MoCTCA, 2019), indicates the progress made over the years. This progress for quantity further suggests the need to promote the quality of tourism by ensuring the safety and security of Nepalese tourism destinations to provide memorable experiences to tourists. Meanwhile, socio-economic development through tourism remains a major focus. In 2019, 
tourism accounted for a national GDP of $6.7 \%$ supporting $6.9 \%$ of total employment (WTTC, 2020). The Government of Nepal was expecting to welcome 2 million international tourist arrivals for 2020 which got interrupted due to the COVID-19 pandemic. With the global health crisis as well as destination specific safety and security needs, the tourism industry demands more attention from the government and relevant tourism stakeholders.

The Kathmandu valley is the starting point of a journey for international tourists. As the only gateway point for international tourists, specific destinations within the valley become important to create a positive image for other destinations across the country. The Kathmandu valley is known to have a rich cultural significance for tourists, which is also on the list of UNESCO world heritage sites (UNESCO, n.d.). Besides cultural heritage sites, one specific tourist destination in the Kathmandu valley is Thamel which has been the main tourist destination since tourism development started in the 1950s. Thamel is a starting and concluding point of attraction for tourists. Owing to this fact, the overall safety and security situation in Thamel not only affects the tourism industry of Thamel, but also the overall tourism industry in Nepal. There is a lack of empirical studies examining the state of safety and security situations in Thamel. This study aims to assess the perceptions of tourists visiting Nepal on the overall safety and security situation of Thamel and provide necessary suggestions and recommendations to improve its security situation.

\section{Literature Review: Tourism and Security}

The tourism industry is highly dependent on the safety and security situation of the country due to its connection with all the activities related to tourism as well as an individual's decision to travel. Tourism security is a comprehensive concept that covers all tangible and intangible entities including people, economics, politics, social, cultural, legal provisions, and natural as well as individual characteristics such as discipline, morals, character, and learning (Sharma, 2017). Bianchi (2006) highlighted that the power to travel globally for recreation or leisure purposes in a relatively safe environment is a recent phenomenon. However, traveling always involves a certain challenge for tourists along with a degree of danger (Bianchi, 2006).

Many authors have explored the concept of tourism security from diverse approaches. Walters et al. (2017) discussed the influence of risk perceptions on destination selection and the travel decision-making process. Further, they stated the nature and significance of risk are different for each destination. Potential tourists can perceive many factors as risky, from terrorist attacks, natural disasters, illnesses, cultural barriers, to poor value for their money (Walters et al., 2017). In line with these thoughts, Larsen et al. (2009) argued tourist perceptions of risk are subjective and introduced the concept of worry to tourism to distinguish between risk and worry. They defined risk as "the probability of certain adverse events times the magnitude of their consequences" (Larsen et al., 2009, p. 260). Therefore, the subjective risk is the individual's belief of the probability that these events occur. On the other hand, worry is a negative emotional response to uncertainty (Walters et al., 2017). Larsen et al. (2009) discussed the presence of worry emotions in tourists. During the travel planning process, individuals engage in chains of thoughts about different uncertain outcomes, including possible negative consequences, and attempt to solve or find alternatives to overcome those issues or ways to avoid them.

Walters et al. (2017) found that Olympic tourists' trust in the destination security authorities helped to reduce risk perceptions or concerns. Similarly, their study found that tourists were more concerned about getting ill with the Zika virus than being victims of crime. This finding is of particular interest because it reflects the predominance of health safety over financial safety, tourists might perceive it harder to recover from an illness than recover from losing some money or belongings. Additionally, some authors have also discussed that loyalty, destination attachment and past experiences play a significant role in reducing risk perceptions of a destination (Walters et al., 2014; Sharifpour et al., 2014). Likewise, Lepp and Gibson (2003) 
observed that tourists with higher preferences for novelty and excitement show significantly lower levels of perceived risk. Kekovic and Markovic (2009) debated that the security of a destination can represent a competitive advantage because of the benefits associated with better security strategies or measures. In line with these thoughts, Berendien (2015) found the negative effects of safety and security on South Africa's competitiveness index. Moreover, among the main factors impacting this destination, health risk was found the most relevant. Other dimensions such as airline taxes, bribery, corruption, and crime were listed as well. For South Africa to become more appealing to international travelers, policymakers were urged to provide new strategies and solutions. Thus, although the main motivations for travel are different than security needs, tourists' safety measures continue to be a must for the image of any destination (Kekovic \& Markovic, 2009).

On the other hand, Bianchi (2006) argued tourists are becoming a target for terrorist attacks. Likewise, Kekovic and Markovic (2009) pointed out, tourists are objects of these strikes due to their connection to traffic and financial centers, big business and corporations, publicity, because of the big fluctuation of capital, merchandise, and people, and last, because they symbolize national culture. Further, Bianchi (2006) also points out the role of tourism in appropriation, enclosure, and degradation of local resources, important for the resident's survival, which turns tourists into a cause of security threats. Griffin (2005) also pointed out there is a need for change in the approach of destination security. He stated that security does not rely only on the government or state, but also on the population, which represents the human dimension of security. While the state develops security policies, the achievement of security relies on individuals which in turn link their security to their economic wellbeing, therefore local community wellbeing is related to significantly lower levels of crime (Griffin, 2005).

\section{Method}

\subsection{Study Context}

After the beginning of a modern era in Nepal, following the downfall of the Rana regime in the 1950s, tourists started to visit Nepal in ever-increasing numbers (Hagen, 1994), until the setback following the September 11 terrorist attacks in the United States. Few foreign tourists visiting Nepal during the 1950s, they were mainly attracted by its cultural heritage and natural beauty. During that time, Nepal was untouched by western modernity and was largely following the simple life based on agrarianism. When the tourists arriving in Nepal during that time returned to their respective home countries, they used to take exotic tales of a hidden Shangri-La nestled in the Himalayas. This word of mouth served as a prism through which the people in other parts of the world viewed and created their perception of Nepal. The first successful ascend of Mt. Everest in 1953 AD by New Zealander Sir Edmond Hillary and Nepali Tenzing Norgay Sherpa further enhanced the alluring image of Nepal which was later informally advertised by travel guides and postcards sent to loved ones. Following this, the arrival of American Peace Corps volunteers and the Western hippies in the early 1960s further helped to explain Nepal's beauty, the lovely nature of the people, and its cultural heritage. These frequent flows of people and the message they take back home with them helped positively to shape the image of Nepal in westerners' minds (Shrestha, 2001).

The history of the tourism industry of Nepal is very short and began with mountain tourism in the 1950s. Nepal was granted membership of the United Nations in 1955, which introduced Nepal on the global scale. In the same year, world-renowned Thomas Cook and Sons brought a group of sixty tourists to Kathmandu for a Nepal tour. These events contributed to the gradual influx of foreign tourists in Nepal and the Kathmandu valley as well (Shrestha \& Shrestha, 2012). Kathmandu is an ancient and historical city. It is famous for its cultural heritage, natural beauty, and good weather (Shrestha \& Shrestha, 2012). Thamel area is the main touristic hub of 
Kathmandu valley but the history of the tourism industry is very short and flourished only after 1968 when Hashish became illegal and the hippie tourism was quickly replaced with the more conventional businesses of trekking and tourism (Sharma, 2017). Before the development of tourism in Thamel, tourists used to hang out on Freak Street around Kathmandu Durbar Square where a large number of hippies used to stroll and mainly indulged in hashish during the 1960s and 1970s. Later, the flow of tourists got shifted towards Thamel with the establishment of Kathmandu Guest House (Bhatta, 2016).

The study area for this research is Thamel from the Kathmandu district of Nepal (Figure 1). Since Thamel represents many tourism destinations of Nepal because of the mass tourists' attraction, conducting this study in Thamel provides a good reflection of Nepal's tourism security. To study tourism security in Nepal, Thamel appears an appropriate place considering the flow of tourists and being a tourist-hub, which attracts almost all the tourists who visit Nepal.

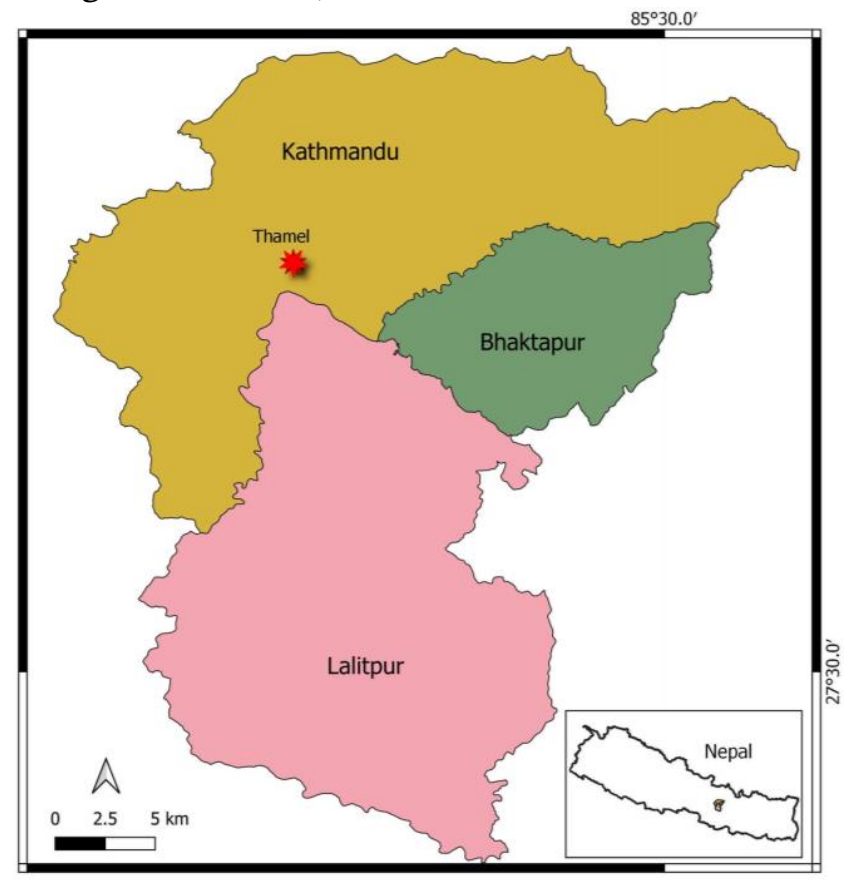

Figure 1: Study area map

\subsection{Data Collection and Analysis}

This study utilized a mixed-methods approach. The data was collected through a questionnaire survey with international tourists. In addition to the survey with the tourists, informal communication with stakeholders was included. Related stakeholders of Thamel include visitors, entrepreneurs, local tourism authorities, hotel employees, tourist police, local police, traffic police, local inhabitants, hawkers, rickshaw owners, and taxi drivers. Meanwhile, direct field observation was used. Field observations were made during the study to obtain information and verify the information regarding tourism security, tourism status, decision-making process, and security management system in summer 2018. Due to the exploratory nature of the study, data analysis includes simple descriptive statistics along with visualizations of the findings created using UCINET-a social network analysis software (Borgatti et al., 2002).

\section{Results}

\subsection{Respondents' Profiles}

Among 103 respondents; the majority were from Europe followed by Asia, North America, Australia, South America, and Africa (Table 1). Most of the respondents fall within the age group of 22 to 35 years old which represents nearly $40 \%$ of all tourists. Most of the tourists visiting Nepal are well educated. Most of the participants in this study had income less than $\$ 5,000$ per 
month. Specifically, nearly $35 \%$ had income less than $\$ 2,000,34 \%$ had income between $\$ 2,000$ and $\$ 5,000$ (Table 1 ).

Table 1: Sociodemographic profile of respondents

\begin{tabular}{ll}
\hline Sociodemographic Indicators & Percentage \\
\hline Origin of Tourists & \\
Europe & 45 \\
Asia & 31 \\
North America & 15 \\
Australia & 5 \\
South America & 3 \\
Africa & 1 \\
\hline Age (Years) & \\
Up to 21 & 13 \\
22-35 & 39 \\
36-55 & 29 \\
$>55$ & 16 \\
Did not respond & 3 \\
\hline Education Level & \\
Primary School & 1 \\
Middle School & 7 \\
High School & 12 \\
Bachelors & 45 \\
Masters and Above & 35 \\
\hline Income (Monthly) & \\
Less than \$2,000 & 35 \\
\$2,001- 5,000 & 34 \\
\$5,001- 10,000 & 19 \\
More than \$10,000 & 5 \\
Did not respond & 7 \\
\hline
\end{tabular}

\subsection{Tourists' Perceptions of Security Arrangements in Thamel}

Most of the respondents (i.e., 72\%) perceived Thamel to be secured (Figure 2). Contrarily, 22\% of respondents felt not very secure and $1 \%$ felt very insecure. This first impression of general security points out that Thamel is mostly perceived as a safe destination, however, a high percentage of respondents still hold a negative perception, indicating a demand for improvement. The Government of Nepal planned to celebrate 2020 as a tourism year with a target to attract two million tourists (Adhikari, 2019), the celebration was later canceled due to COVID-19. However, similar programs should also include security issues in the planning process so that tourists feel secure at Thamel. This will positively affect the word of mouth advertisement and will have a ripple effect and will contribute to the development of tourism in Nepal.

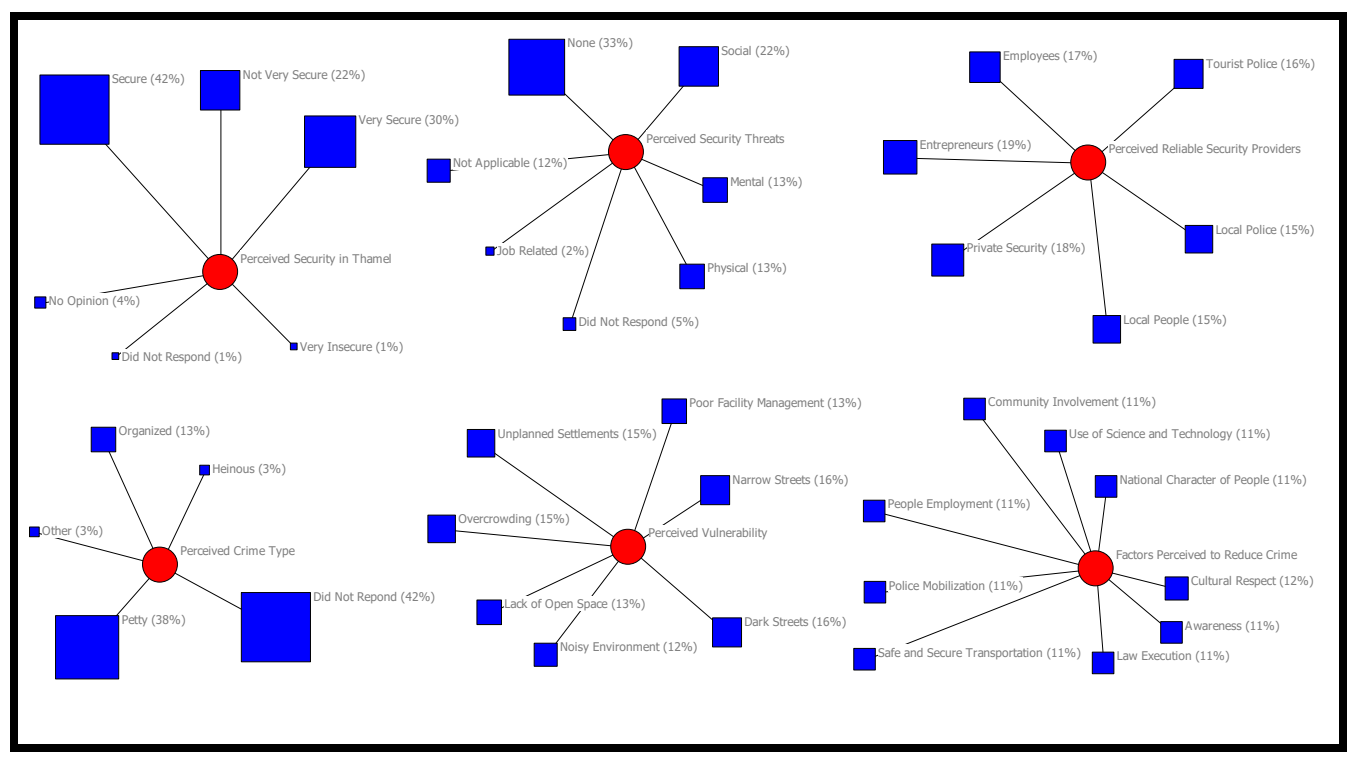

Figure 2: Perceived security arrangements in Thamel [Figure shows the responses in percentages for different categories of security-related questions] 
As illustrated in Figure 2, 38\% of the respondents expressed that petty crime was the one mainly occurring in Thamel, while 13\% perceived that organized crime was occurring as well. Some respondents (i.e., 3\%) perceived that heinous crimes exist. Since a lot of petty crimes are occurring in Thamel, effective mobilization of police needs to be enhanced. Increasing the number of surveillance cameras scattered throughout Thamel, mainly in areas where there is less human movement during the nighttime, might also help curb down these problems. Increasing the light in less frequently used areas will also help reduce some of the crimes. To reduce the heinous crime, security personnel need to conduct more surveillance activities, without giving unnecessary burden to the business and local tourists; and target specific areas where it is likely to occur more. The addition of closed-circuit security cameras in major areas of Thamel might help reduce the crime. These recommendations are in line with Walters et al. (2017) who found that Olympic tourist trust in the destination security authorities helps to reduce risk threats, particularly those related to crime events. However, as discussed by Muehsam and Tarlow (1995), it is important for local and national authorities to "develop a well-rounded security plan" which considers fiscal and social limitations inherent to tourism businesses such as hotels, restaurants, and attractions.

Regarding the type of security threat, one third (i.e., 33\%) of the respondents perceived no security threat (Figure 2). However, $22 \%$ perceived social reasons as the main security threat. This finding is not surprising, because international travelers face many cultural and linguistic differences that might make them feel more vulnerable (Muehsam \& Tarlow, 1995). Likewise, both mental and physical (i.e., each 13\%) are perceived to be security threats. Overall, these threat perceptions can be associated with a certain degree of xenophobia due to the uniqueness of the culture in Nepal. Thus, given the different dimensions of the perceived security threats, it is essential to take this matter seriously and develop a program to make all tourists feel at home. Actions should be taken to reduce the unwanted problems prevailing at Thamel. First, the police should be required to understand the relevance of tourism and be trained to identify tourists' security needs (Muehsam \& Tarlow, 1995).

The respondents were asked about the contributors to increased vulnerability factors in Thamel. Among the seven contributors identified in the questionnaire, dark and narrow streets were found to be the highest contributor to increased vulnerability in Thamel tourism security (Figure 2). Naturally, more crime occurs in places where there are not enough lights. Meanwhile, overcrowding and other contributors are equally perceived to increase the vulnerability in terms of security threats in Thamel. Likewise, the respondents were asked about their perception of the most reliable security provider. Respondents perceived entrepreneurs (e.g., local tourism business owners) to be the most security provider (i.e., 19\%) followed by private security (i.e., 18\%), employees (i.e., 17\%), tourist police (i.e., 16\%), local people (i.e., 15\%), and local police (i.e., $15 \%$ ), respectively (Figure 2). This finding is consistent with Griffin's (2005) suggestions for the implementation of a destination security approach in which not only the local authorities and law enforcement but also tourism stakeholders such as hotel and restaurant owners as well as the community are part of the security system.

The respondents were asked about the factors important in reducing crime in Thamel. The choices presented were national character of people, safe and secure transportation, respect culture, law execution, awareness, police mobilization, using science $\&$ technology, community involvement, and people employment. All the factors are equally perceived to be important in reducing the crime in Thamel (Figure 2).

\section{Discussion and Conclusion}

Nature, culture, infrastructure, connectivity, and security are major pillars of tourism development (Sharma, 2017). This research was mainly focused on the safety and security aspect of the tourism industry, especially in the Thamel area of Kathmandu valley, Nepal. This research 
sought to cover overall security perceptions and concerns faced by the tourism industry of Thamel. Overall, the findings suggest that the security situation is satisfactory, but still there are areas for improvement. The findings suggest that there are several safety and security challenges in Thamel. With the Government of Nepal's vision to increase the number of tourists to Nepal to two million, several security arrangements need to be improved in advance. Berendien (2015) suggested that to attract more international tourists, the establishment of important safety and security policies is imperative and provides the destination a competitive advantage. As discussed before, there are several dimensions to tackle. First, to address the physical factor of security threats, the identification of specific security threats of the Thamel tourism industry is required. The results provided evidence of the perceptions of crime within the destination, some alternatives to reduce these risks are the addition of surveillance cameras, working in publicprivate partnerships with entrepreneurs in Thamel, and the effective mobilization of all government resources including local people, local police, tourists police, Armed Police Force (APF)-Nepal, and private security.

Furthermore, the stakeholders included in the information communication held at Thamel Tourism Development Council (TTDC) agreed that the installment of security cameras in different places of Thamel will help to improve the security situation of Thamel. They also highlighted that it was the first discussion held in Thamel where all the concerned stakeholders were gathered at one place; including the representative of those groups who is being blamed to create security problems frequently. All the participants agreed that TTDC needs to organize these types of interactions and take more leadership roles to further develop Thamel as a tourism destination. This is consistent with Griffin (2005) who debated that tourism security plans must be developed with the participation of all stakeholders, especially the local community and tourism businesses need to take advantage of the law enforcement bodies and cooperate with them. Finally, the findings showed that the major security concerns of the Thamel area are junkies, homeless children, unregulated hawkers, and poor traffic management. These issues should be managed by making both short and long-term strategies.

On the other hand, the study also found that people perceive the social dimension as the main source of threat or risk. Muehsam and Tarlow (1995) pointed out that international travelers are most likely to face cultural and linguistic barriers. Given the uniqueness of Nepal's culture, it is not surprising that tourists confront difficulties when visiting the city. Thus, it is reasonable that participants showed social and mental security threats. Further, this finding is in line with Walters et al. (2017) who stated that tourists can perceive many factors as risky, from physical threats like terrorist attacks, natural disasters, or illnesses, to social and mental sources such as cultural barriers. Therefore, besides working on a security program focused on crime reduction, Thamel tourism authorities need to develop strategies seeking to reduce cultural/linguistic limitations. This can be addressed by developing cultural programs to create awareness among the community regarding the importance of the tourism industry for the local economy, motivating local people to preserve and share their unique traditions with international travelers.

Finally, a general local plan for tourism security in Thamel should include all the factors identified as relevant by the respondents: national character of people, safe and secure transportation, respect for culture, law execution, awareness, police mobilization, using science \& technology, community involvement, and people employment. Overall, the current perceptions of security are good, however, several factors showed the necessity to be improved. By creating a plan that would set the goals, objectives, and strategies to lead Nepal in achieving their purpose of attracting two million international tourists.

\section{Implications and Future Research}

This exploratory study delves into security issues in a tourism hub of Kathmandu valley, Thamel. It holds significant importance despite the exploratory nature of the study because perceived 
safety and security concerns among tourists in Thamel affect tourists' visitations to other tourism destinations of Nepal as well as their re-visit intentions. As Thamel is the first point of contact for tourists, sustainable management of Thamel is important to positively influence the growing tourism industry in Nepal. Therefore, an important avenue for future research includes an understanding of how the safety and security concerns among the tourists impact their intention to explore other destinations of Nepal. Further, it would be important to assess the importance of Thamel and its environment in either catalyzing or deterring the exploration of tourism experiences. Indeed, there is a need to emphasize the importance of tourism in Thamel and its impact on national tourism.

This study only looks at the perceived security arrangements in Thamel from tourists' perspectives. However, it is equally important to assess the community perception of the tourism development phenomena in Thamel and beyond, as they are another major stakeholder significantly impacted by tourism, regardless of their participation or non-participation in tourism. The community involvement and their perceived benefits from the industry also determine their behavior towards tourists. Thus, their role with the destination security could be another avenue for future studies that holds significant potential to offer managerial implications. It is not uncommon that the community equally fears tourism, as mass tourism destinations violate the community's sense of place and social capital. Their inclusion in the tourism development process and greater involvement in benefit-sharing is important. Thamel should be assessed within the lens of the community to ensure the long-term sustainability of the industry. Meanwhile, it is important to realize that the sustainable management of tourism destinations is possible with the synergistic collaboration among all relevant stakeholders beyond tourists and the community. Different stakeholders identified in Thamel have equal responsibility in ensuring a safe and secured place. Looking at the tourism phenomena in Thamel through a lens of stakeholder analysis will provide a holistic picture for future directions.

\section{Acknowledgment}

We would like to thank all the study participants and other participating stakeholders for sharing their views with us. We would also like to thank Hari Adhikari for providing the study area map. We also thank the anonymous reviewers for their valuable feedback.

\section{Funding}

This research received no external funding

\section{Conflicts of Interest}

The author(s) declare no conflict of interest

\section{References}

Adhikari, S. (2019). Prospects of tourism in Nepal: A study of Pokhara city. A thesis is submitted to $\begin{array}{llll}\text { University of Applied Science. } & \text { Retrieved }\end{array}$ https://www.theseus.fi/handle/10024/165831.

Berendien, A. L. (2015). Measuring the competitiveness of South Africa as a tourist destination. Travel and Tourism Research Association: Advancing Tourism Research Globally, 12.

Bhatta, C. (2016). The Role of Arts in Promoting Tourism: A Case of tourism Development in Thamel Area. Journal of Advanced Academic Research, 3(1), 177-184.

Bianchi, R. (2006). Tourism and the globalisation of fear: Analysing the politics of risk and (in)security in global travel. Tourism and Hospitality Research, 7(1), 64-74.

Borgatti, S. P., Everett, M. G., \& Freeman, L. C. (2002). UCINET 6 for Windows: Software for Social Network Analysis. Harvard, MA: Analytic Technologies. 
Gammon, S., \& Robinson, T. (2003). Sport and tourism: A conceptual framework. Journal of Sports and Tourism, 8(1), 21- 26.

Garcia-Altes, A. (2005). The development of health tourism services. Annals of Tourism Research, $32(1), 262-266$.

Garg, A. (2015). Travel risks vs tourist decision making: A tourist perspective. International Journal of Hospitality \& Tourism Systems, 8(1), 1-9.

Griffin, C. E. (2005). The imperatives of regional governance: Securing the tourism sector and enhancing human security. Social and Economic Studies, 54(4), 13-41.

Hagen, T. (1994). Building Bridges to the Third World: Memories of Nepal, 1950-1992. Delhi: Book Faith India.

Hall, C. M., Scott, D., \& Gössling, S. (2020). Pandemics, transformations and tourism: be careful what you wish for. Tourism Geographies, 22(3), 577-598.

Hall, C. M., Timothy, D. J., \& Duval, D. T. (2004). Security and Tourism. Journal of Travel \& Tourism Marketing, 15(2-3), 1-18.

KC, B. (2020). Ecotourism for wildlife conservation and sustainable livelihood via communitybased homestay: a formula to success or a quagmire? Current Issues in Tourism, Online First: https://doi.org/10.1080/13683500.2020.1772206

KC, B., Paudyal, R., \& Neupane, S. S. (2018). Residents' perspectives of a newly developed ecotourism project: an assessment of effectiveness through the lens of an importanceperformance analysis. Asia Pacific Journal of Tourism Research, 23(6), 560-572.

Kekovic, Z., \& Markovic, S. (2009). Security as a factor of competitive advantage in tourism. Tourism \& Hospitality Management, 15(2), 291-303.

Kovari, I., \& Zimányi, K. (2011). Safety and security in the age of global tourism (The changing role and conception of safety and security in tourism). Applied Studies in Agribusiness and Commerce, 5(3-4), 59-61.

Larsen, S., Brun, W., \& Øgaard, T. (2009). What tourists worry about - Construction of a scale measuring tourist worries. Tourism Management, 30, 260-265.

Lepp, A., \& Gibson, H. (2003) Tourist roles, perceived risk and international tourism. Annals of Tourism Research, 30, 606-624

Min, J., KC, B., Kim, S., \& Lee, J. (2020). The impact of disasters on a heritage tourist destination: A case study of Nepal earthquakes. Sustainability, 12(15), 6115.

MoCTCA (2019). Nepal Tourism Statistics 2018. Singha Durbar, Kathmandu, Nepal.

Muehsam, M. J., \& Tarlow, P. E. (1995). Involving the police in tourism. Tourism Management, 16(1), 9-14.

Rasul, G., \& Manandhar, P. (2009). Prospects and problems in promoting tourism in South Asia: A regional perspective. South Asia Economic Journal, 10(1), 187-207.

Sharifpour, M., Walters, G., Ritchie, B., \& Winter, C. (2014). Investigating the role of prior knowledge in tourist decision making: A structural equation model of risk perceptions and information search. Journal of Travel Research, 53(3), 307-322.

Sharma, A. K. (2017). State of Tourism Security in Pokhara Valley. Saarbrucken: Lambert Academic Publishing.

Shrestha, H., \& Shrestha, P. (2012). Tourism in Nepal: A historical perspective and present trend of development. Himalayan Journal of Sociology and Anthropology, 5, 54-75.

Shrestha, N. (2001). Political Economy of Land, Landlessness and Migration. Delhi: Nirala Publication.

UNDP (2007). Lessons Learned: Nepal's Experience Implementing Sustainable Rural Tourism Development Model of Tourism for Rural Poverty Alleviation Program. Retrieved from https://www.np.undp.org/content/nepal/en/home/library/poverty/lessons-learned-nepal-s-experience-implementing-sustainable-rur.html 
UNESCO (n.d.). Properties inscribed on the World Heritage List: Nepal. Retrieved from https://whc.unesco.org/en/statesparties/np

Walter, P., Regmi, K. D., \& Khanal, P. R. (2018). Host learning in community-based ecotourism in Nepal: The case of Sirubari and Ghalegaun homestays. Tourism Management Perspectives, 26, 49-58.

Walters, G., Mair, J., \& Ritchie, B. (2014). Understanding the tourist's response to natural disasters: The case of the 2011 Queensland floods. Journal of Vacation Marketing, 21 (1), 101113.

Walters, G., Shipway, R., Miles, L., \& Aldrigui, M. (2017). Fandom and risk perceptions of Olympic tourists. Annals of Tourism Research, 66, 210-212.

WTO (2020). International Tourism 2019 and Outlook for 2020. UNWTO, Madrid.

WTTC (2020). Economic Impact Reports. Retrieved from_https://wttc.org/Research/EconomicImpact 